\title{
FOURTH INDUSTRIAL REVOLUTION - IMPLEMENTING FOURTH GENERATION SCADA WITH THE REVOLUTIONIZING TECHNOLOGY OF INTERNET OF THINGS
}

\author{
R. Amudhevalli \\ Department of Electronics \\ Rathnavel Subramaniam College of Arts and Science, \\ Sulur, Coimbatore, Tamilnadu, India.
}

\begin{abstract}
Digitization is a major driving force of our time, turning our world inside out. Smart and connected systems are increasingly pervading all types of applications. The internet of things (IoT) is already starting to affect environments of all kinds - homes, cities, travel, logistics, retail and medicine, to name just a few - and it will not stop at our factory gates, either. According to a recent estimation by McKinsey, the potential economic impact of IoT applications in 2025 is between US\$ 3.9 and \$11.1 trillion, of which $\$ 1.2$ to $\$ 3.7$ trillion is allotted to IoT applications within the factory environment. Also known as smart manufacturing, or Industrie 4.0 in Germany, these are fully networked manufacturing ecosystems driven by the IoT . In a future where all "factory objects" will be integrated into networks, traditional control hierarchy will be replaced by a decentralized self-organization of products, field devices and machines. Production processes have to become so flexible that even the smallest lot size can be produced costeffectively and just in time to the customer's individual demands. Customers are driving this development too, as they can design and order products at the click of a mouse. They can also expect their products to be delivered within a few days - or even hours - and don't want to wait weeks for goods to travel from far regions of the world where labour costs are lower.
\end{abstract}

Keywords-IOT, Industrie 4.0 and smart manufacturing

\section{INTRODUCTION}

The Internet of Things is a culmination of advances in connectivity hardware, data networks, cloud computing and big-data processing. IoT begins where SCADA, DCS, and Historians end. Manufacturing is a mature industry with machines and assembly lines that run with a high degree of automation. Supervisory Control \& Data Acquisition Systems (SCADA) and Distributed Control Systems (DCS) are prevalent industry standards. IoT relevant to manufacturing and it is a critical part of Industry 4.0 initiative.

\author{
Dr. T. Sivakumar, \\ Principal, Department of Electronics, \\ Rathnavel Subramaniam College of Arts and Science, \\ Sulur, Coimbatore, Tamilnadu, India.
}

IoT is complementary to SCADA and DCS. Information generated from SCADA systems acts as one of the data sources for IoT. SCADA's focus is on monitoring and control. IoT's focus is firmly on analyzing machine data to improve productivity and impact top line. Essentially, IoT should be viewed as a technology that is implemented on top of SCADA. It makes things like scalability, data analytics, standardisation and interoperability realities.

Co-founder and CEO of IoT ., Nico Steyn, noted that "in fact, IoT is what's going to bring SCADA systems to the next level. Instead of fighting against each other, the two technologies can instead integrate to push industry even closer to the edge."

\section{THE INTERNET OF THINGS}

The Internet of Things is a network of physical objects - vehicles, machines, home appliances, and more - that use sensors and APIs to connect and exchange data over the Internet.

What makes the IoT possible?

The IoT depends on a whole host of technologies such as application programming interfaces (APIs) that connect devices to the Internet. Other key IoT technologies are Big Data management tools, predictive analytics, AI and machine learning, the cloud and radio-frequency identification (RFID).

IoT platforms and architecture

Cloud-based IoT platforms and architecture connect the real and virtual worlds. They help companies manage IoT device connectivity and security - as well as collect device data, link devices to backend systems, ensure IoT interoperability, and build and run IoT applications.

Harnessing the IoT data explosion

Smart devices generate a massive amount of IoT data that needs to be analysed and leveraged in real time. This is where predictive and Big Data analytics come into play. Machine learning is also used to add context to data - and trigger actions without human intervention. 


\section{International Journal of Engineering Applied Sciences and Technology, 2019 \\ Vol. 4, Issue 5, ISSN No. 2455-2143, Pages 199-201 \\ Published Online September 2019 in IJEAST (http://www.ijeast.com)}

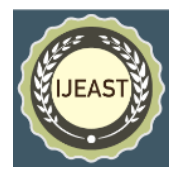

\section{The Industrial Internet of Things (IIoT) \& M2M}

In manufacturing, the IoT becomes the Industrial Internet of Things (IIoT) - also known as the Industrial Internet or Industry 4.0. The IIoT uses machine to machine (M2M) technology to support everything from remote monitoring and telemetry to predictive maintenance.

\section{BENEFITS OF THE INTERNET OF THINGS}

\section{New business models and revenue}

Automatic product replenishment? Subscription services? Apps? The IoT is disrupting traditional business models and creating massive opportunities for companies to create new services based on real-time sensor data and information.

\section{Operational efficiency}

One of the biggest benefits of the IoT is the efficiency it can offer. Many companies are using it to automate business and manufacturing processes, remotely monitor and control operations, optimise supply chains and conserve resources.

\section{Workforce productivity}

Wearables and other IoT-enabled devices are boosting workforce productivity and job satisfaction in many verticals. The technology is helping employees improve decision making, automate routine tasks, fast-track communication and more.

\section{Enhanced customer experiences}

From integrating customer care with actual product performance and usage, to delivering highly personalised products and services, the IoT offers many ways to create more compelling customer experiences across digital and physical worlds.

\section{IOT USES}

The Internet of Things is having a profound impact on many different industries and lines of business. Here are three sectors leading the way:

\section{Manufacturing}

The Industrial Internet of Things (IIoT) is completely transforming the way products are made. Manufacturers are using the IIoT and M2M communication to drive industrial automation, predict and prevent equipment failures, improve worker safety and much more.

\section{Transportation}

Intelligent transportation systems are moving people and cargo from A to $\mathrm{Z}$ all over the world. Thousands of IoT sensors are used on planes, trains, ships and vehicles to optimise everything from engine performance and safety to logistics and supply chain management.

\section{Automotive}

Car manufacturers and tech companies are using the IoT to help drivers in connected cars (or smart cars) avoid accidents, predict maintenance issues, find parking spots and more. The IoT and machine learning are also bringing selfdriving cars to the market.

\section{THE COMPARATIVE ANALYSIS}

In the end, both SCADA and IoT involve sensors and data acquisition. Although they do differ in many aspects, they both share the one common goal. The optimization of use and eventually, better control over some devices or a process. The whole idea of a smart grid leads to SCADA and IoT integration. As SCADA is not a full control system, rather a computer system that gathers and analyses real-time data, it is useful in monitoring and controlling a plant or industrial equipment. It will gather information about a mishap, transfer it back to a central site and alert the home station. It will then carry out any necessary analysis and control and display the information in a logical and organized fashion for humans to then interpret and use accordingly.

The Internet of Things is made up of a network of physical devices connected via electronic embedding, software setups, sensor-actuators and network connectivity which all act together for the objects to connect and exchange data. IoT allows objects to be sensed or controlled remotely across different networking infrastructures. Therefore, it creates opportunities for more direct integration of the physical world into computer-based systems. This results in improved efficiency, accuracy and economic benefit and also cuts down on human intervention.

Both platforms offer an abundance of advantages, as well as some vulnerabilities. It is predicted that by 2020, 50 billion devices or things will be connected to the internet. Therefore, the dynamics of an Internet-based control system are becoming a living reality. Industry 4.0 is an era in which emerging trend automation and data exchange in manufacturing technologies are allowing for a shift from traditionally implemented SCADA to an IoT implemented one. With SCADA, cyber-physical systems, the Internet of Things, cloud computing and cognitive computing, Industry 4.0 is an era that will change the dynamics of the entire automation industry.

\section{CONCLUSION}

Industry 4.0 is a term the German government coined to describe the new Smart Factory: Computerization of manufacturing. It suggests that four design principles, which leverage nine pillars of Industry 4.0, are catalyzing the 4th Industrial Revolution. Industry 4.0 is often used synonymously with Manufacturing 4.0.According to BCG (Boston Consulting Group), the nine pillars of Industry 4.0 are:

Autonomous Robots; Big Data; Cloud Computing; Internet of Things (IoT \& IIoT); Cybersecurity; System Integration; Simulation; Augmented Reality (and Virtual Reality); Additive Manufacturing (e.g., 3D printing)

A key benefit of this 4th Industrial Revolution is masscustomization: The ability to deliver customized products with standard lead-times and in low volume, high-mix production environment. 


\section{International Journal of Engineering Applied Sciences and Technology, 2019 \\ Vol. 4, Issue 5, ISSN No. 2455-2143, Pages 199-201 \\ Published Online September 2019 in IJEAST (http://www.ijeast.com)}

\section{REFERENCE}

[1] Qing ping Chi, Hairong Yan, Chuan Zhang, Zhibo Pang, and Li Da Xu,(May 2014) "A Reconfigurable Smart Sensor Interface for Industrial WSN in IoT Environment," IEEE Transactions on Industrial Informatics, (vol. 10, no.2,pp.1417-1425,.)

[2] Wang L., Xu, L. Z. Bi, and Xu.Y, (February 2014) "Data cleaning for RFID and WSN integration," IEEE Transactions on Industrial Informatics, (vol. 10, no. 1, pp. 408-418)

[3] Fan.Y, Yin.Y,Xu,Y,Zeng.Y, and Wu,F,"IoT based smart rehabilitation system," (2014) IEEE Transaction on Industrial Informatics, (vol.10,no.2,pp. 1568-1577).

[4] Li.S,Da.LXu, and Wang.X, ( Nov. 2013). "Compressed sensing signal and data acquisition in wireless sensor networks and internet of things," IEEE Transaction on Industrial Informatics., (vol. 9, no. 4, pp. 2177-2186).

[5] Lazarescu.M.T,(March 2013). "Design of a WSN platform For longterm environmental monitoring for IoT applications,"IEEE Journal On Emerging And Selected Topics In Circuits And Systems, ( Vol. 3, No. 1 pp. 4555)

[6] Kelly.S.D.T.,Suryadevara.N, and Mukhopadhyay.S.C, (Oct.2013),Towards the Implementation of IoT for Environmental condition monitoring in homes," IEEE Sensors Journal. (vol. 13, no. 10, pp. 3846-3853,.)

[7] J. Zhou et al.,(Aug.2013) "An efficient multidimensional Fusion algorithm for IoT data based on partitioning," Tsinghua Science and Technology. ( vol. 18, no. 4, pp. 369-378)

[8] Wattics, - Smartmetering,(2011), http://www.wattics.com/

[9] Cantaloupe Systems, —Seed Platform, $\|$ (2012) http://www.cantaloupesys.com/

[10] ENGAUGE, —Remote Fire Extinguisher Monitoring System,ll. Retrieved from http://engaugeinc.net/fireextinguisher-monitoring

[11] Gubbi.J,Buyya,R Marusic.S,Palaniswami.M.P., , (September 2013)-Internet of Things (IoT): A Vision, Architectural Elements, and Future Directionsll Future Generation Computer Systems (Volume 29, Issue 7, Pages

$1645-1660)$

[12] Internet of Things Technologies . Retrieved from www.postscapes.com/iot

[13] The internet of things challenges and opportunities. Retrieved from http://sandhill.com/article/the-internet-ofthings-challenges-andopportunities/

[14] Cognizant Report Reaping the Benefits of the Internet of Things. Retrieved from http://www.cognizant.com/InsightsWhitepapers/ReapingtheBenefits-of-the-Internet-of-Things.pdf

[15] Wikipedia website, https://en.wikipedia.org/wiki/MQTT.

[16] Suciu, G., Vulpe, A., Halunga, S., Fratu, O., Todoran, G., \& Suciu, V.(2013, May). Smart cities built on resilient cloud computing and secure internet of things. In Control Systems and Computer Science (CSCS),(pp. 513-518). 